$2021-12-13$

Impact of growth media and pressure on the diversity and antimicrobial activity of isolates from two species of hexactinellid sponge

Koch, MJ

http://hdl.handle.net/10026.1/18527

10.1099/mic.0.001123

Microbiology

Microbiology Society

All content in PEARL is protected by copyright law. Author manuscripts are made available in accordance with publisher policies. Please cite only the published version using the details provided on the item record or document. In the absence of an open licence (e.g. Creative Commons), permissions for further reuse of content should be sought from the publisher or author. 


\title{
Impact of growth media and pressure on the diversity and antimicrobial activity of isolates from two species of hexactinellid sponge
}

\author{
Matthew J. Koch ${ }^{1, *}$, Poppy J. Hesketh-Best², Gary Smerdon ${ }^{3}$, Philip J. Warburton ${ }^{1}$, Kerry Howell ${ }^{2}$ and Mathew Upton ${ }^{1}$
}

\begin{abstract}
Access to deep-sea sponges brings with it the potential to discover novel antimicrobial candidates, as well as novel cold- and pressure-adapted bacteria with further potential clinical or industrial applications. In this study, we implemented a combination of different growth media, increased pressure and high-throughput techniques to optimize recovery of isolates from two deep-sea hexactinellid sponges, Pheronema carpenteri and Hertwigia sp., in the first culture-based microbial analysis of these two sponges. Using $16 \mathrm{~S}$ rRNA gene sequencing for isolate identification, we found a similar number of cultivable taxa from each sponge species, as well as improved recovery of morphotypes from P. carpenteri at $22-25^{\circ} \mathrm{C}$ compared to other temperatures, which allows a greater potential for screening for novel antimicrobial compounds. Bacteria recovered under conditions of increased pressure were from the phyla Proteobacteria. Actinobacteria and Firmicutes, except at $4 \% \mathrm{O}_{2} / 5$ bar, when the phylum Firmicutes was not observed. Cultured isolates from both sponge species displayed antimicrobial activity against Micrococcus luteus, Staphylococcus aureus and Escherichia coli.
\end{abstract}

\section{INTRODUCTION}

The worldwide threat to public health posed by drug-resistant bacteria has become increasingly apparent over the last decade, with a seminal UK report predicting that deaths attributable to drug-resistant bacteria will rise from 700000 per year to 10 million by 2050 [1]. Additionally, issues with the supply chain of new antibiotics has become a major contributor to the inability to treat microbial infections [2]. Prior to the discovery of teixobactin, identified through the employment of novel culture techniques [3], no novel class of antibiotics had been discovered in several decades. Most current antibiotics have been derived from the natural environment [2], and while it will continue to be an important source for future compounds, there is a need to innovate by investigating underexplored areas and improving culture methodology.
Sponges (Porifera) are sessile metazoan organisms thought to have emerged around 600 million years ago $[4,5]$. As filterfeeding organisms, certain species have been predicted to filter up to 50000 litres of seawater per litre of sponge per day [6], bringing them into contact with large quantities of marine debris, nutrients and planktonic bacteria. Representing the most widely sampled marine phyla in the hunt for novel bioactives over the last 45 years, the Porifera comprise the most prolific source of such agents from the marine environment $[7,8]$. Both culture-dependent and culture-independent studies have been used to reveal the interspecific and intraspecific differences between the microbiota of different sponge species, as well as their antimicrobial potential [9-11].

The cultivation of sponge-associated microbes has traditionally been limited by poor access to samples [12] or difficulty in providing suitable culture parameters $[13,14]$. Efforts to improve the cultivation have included an analysis of different methodologies, such as agar-based recovery [10], the use of

Received 08 August 2021; Accepted 03 November 2021; Published 13 December 2021

Author affiliations: ${ }^{2}$ School of Biomedical Sciences, University of Plymouth, Plymouth PL4 8AA, UK; ${ }^{2}$ School of Biological and Marine Sciences, University of Plymouth, Plymouth PL4 8AA, UK; ${ }^{3}$ Diving Diseases Research Centre Healthcare, Plymouth Science Park, Research Way, Plymouth PL6 8BU, UK.

*Correspondence: Matthew J. Koch, matthew.koch@plymouth.ac.uk

Keywords: sponge; natural product discovery; hexactinellid; antimicrobial; culture.

Abbreviations: ABC, ABC agar; ASV, amplicon sequence variant; DGC, diffusion growth chamber; DTE, dilution to extinction; FSSW, filter sterilized seawater; LB, LB agar; LC, LB + carnitine; LNHM, low-nutrient heterotrophic media; MA, marine agar; MC, marine agar + carnitine; NSW, natural seawater; OM, oatmeal agar; OTU, operational taxonomic unit; PBS, phosphate-buffered saline; RC, R2a agar + carnitine; ROV, remotely operated vehicle; SSE, sponge spicule extract; SYP-SW, starch-yeast-peptone seawater agar.

GenBank accession numbers: MZ723441 to MZ723479.

Four supplementary tables and five supplementary figures are available with the online version of this article. $001123 \odot 2021$ The Authors 


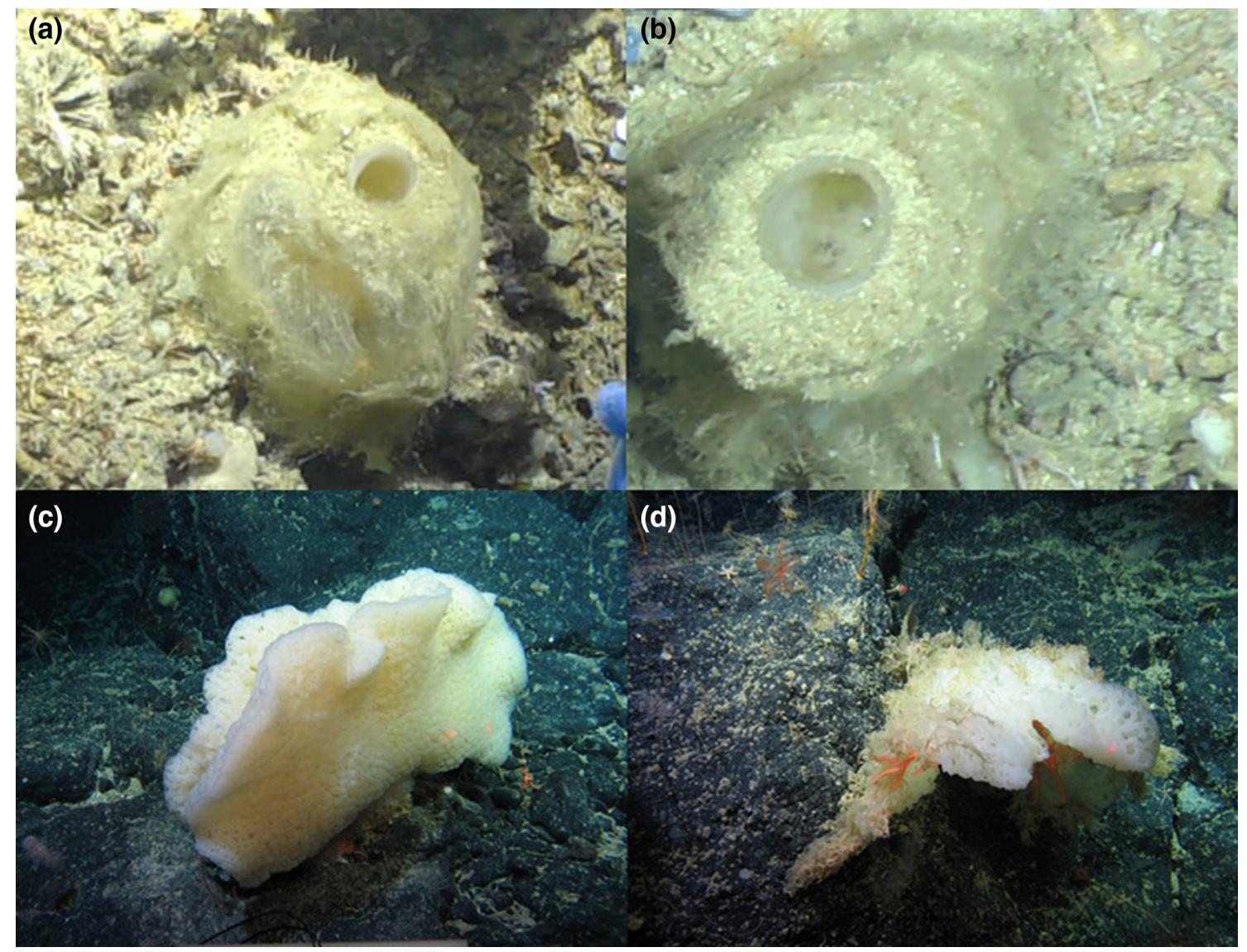

Fig. 1. Photos of sponges taken in situ before sample collection. (a, b) Pheronema carpenteri sponges (JC136). (c, d) Hertwigia sp. sponges (GRNL17).

diffusion chambers [15], liquid culture and floating-filter cultivation [16]. Agar-based methods have shown greater success in cultivating an increased bacterial diversity from Haliclona species, compared to liquid and floating-filter methods [16]. In situ implantation of diffusion growth chambers (DGCs) within the living tissue of Rhabdastrella globostellata sponge have also resulted in the improved recovery of bacteria belonging to the Actinobacteria, Alphaproteobacteria and Gammaproteobacteria [15], many of which were deemed to be novel. This represents a promising method for the cultivation of bacteria from larger, shallow-water sponges, but the in situ nature of the methodology would make implementation on deep-sea sponges more problematic.

For every depth increase of $10.06 \mathrm{~m}$, pressure increases one atmosphere. Therefore, the retrieval of sponge samples from deeper waters brings with it the potential to isolate bacteria adapted to life at both lower temperatures and higher pressures. Bacteria adapted to survive in such conditions can be separated into several categories. Piezotolerant bacteria are those capable of surviving at increased atmospheric pressures, but at which their optimal growth does not occur. In contrast, piezophilic bacteria grow more favourably at higher pressure, while hyperpiezophilic are those that only grow at increased atmospheric pressure [17]. Whilst research has revealed the extent to which piezotolerant/piezophilic bacteria participate in ecological cycles such as nutrient cycling and degradation [18], it has been remarked upon that the effect of hostmicrobe interactions on the ability of bacteria to thrive under increased atmospheric pressures is poorly understood [19]. To the best of our knowledge, the use of increased atmospheric pressure to improve the cultivability of sponge bacteria has not yet been explored.

Hexactinellid, or 'glass', sponges represent an extremely underexplored class of Porifera, in relation to their microbiota and the bioactive potential of associated microbes [20,21]. Occurring almost exclusively below $200 \mathrm{~m}$, hexactinellid sponges are characterized by a 'fused', or basket-like skeleton, consisting of siliceous spicules. Most culture-dependent studies to date have focused on sponges obtained from shallow waters, predominately those of the Demosponge population. Mangano et al. [20], however, first reported the recovery of bacterial isolates from a deep-sea hexactinellid sponge (Anoxycalyx joubini), in a study that included both demosponges and the hexactinellids. Similarly, Xin et al. [21] reported the cultivation of bacterial isolates from two species of Hexactinellid sponges, Rossella nuda and Rossella 
(a)

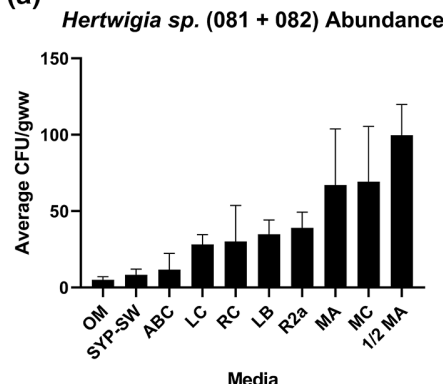

(d)

Pheronema carpenteri $(125+134)$ Abundance

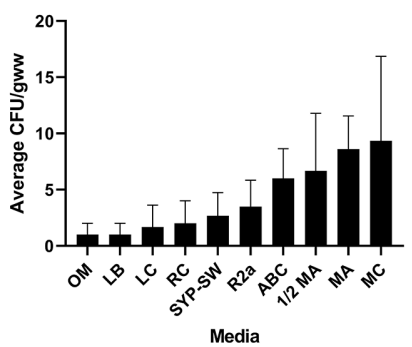

(b)

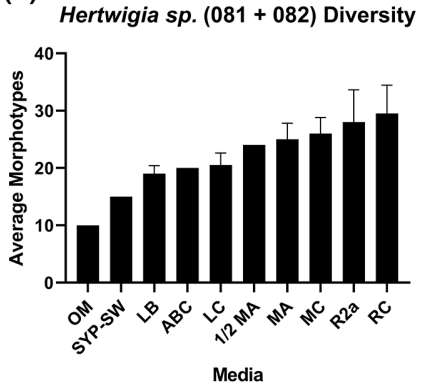

(e)

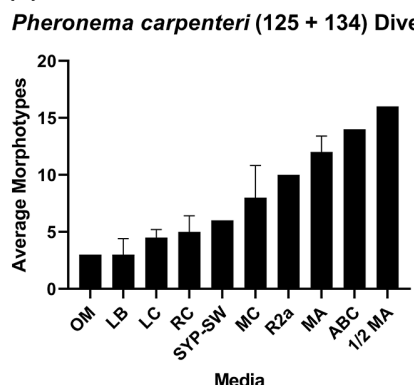

(c)

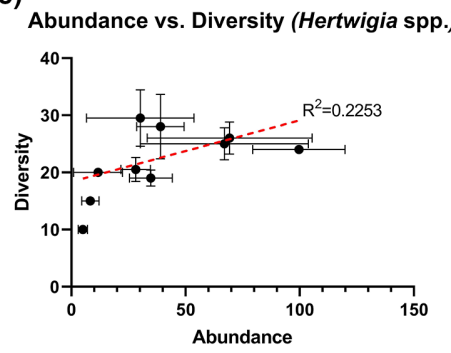

(f)

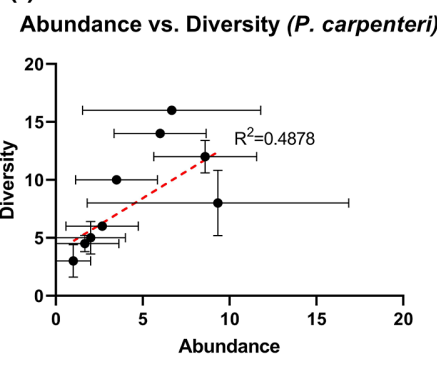

Fig. 2. Recovered c.f.u. gww $w^{-1}$ counts for isolates obtained from two different samples of two species of hexactinellid sponge. (a, d) Abundance counts for bacteria grown across different media for Hertwigia sp. and P. carpenteri, respectively. Bars: mean+SD. (b, e) Number of bacterial morphotypes grown across different media for Hertwigia. sp. and $P$. carpenteri, respectively. Media without bars represent counts taken only for GRNL_081. (c, f) Linear regression analysis between c.f.u./morphotypes obtained across different media for Hertwigia sp. and P. carpenteri, respectively (dots represent individual growth media). Bars represent SD. All media were inoculated in triplicate. The number in parentheses in individual graph titles represents sponge replicate ID. Abbreviations: OM, oatmeal agar; SYP-SW, starch-yeast-peptone-seawater agar; ABC, 'ABC' agar; LC, LB+carnitine hydrochloride; RC, R2A+carnitine hydrochloride; LB, LB agar; MA, marine agar; MC, marine agar+carnitine.

racovitzae, including the cultivation of a potentially novel group of previously uncultured isolates. This suggests a potentially distinct hexactinellid-specific microbiota and is further supported by recent $16 \mathrm{~S}$ rRNA amplicon sequencing and metagenomic surveys [22-24]. The evidence that bacterial genomes associated with Vazella pourtalesii display genome reduction is potentially indicative of specialized, hexactinellid-specific host-microbe interactions [23]. These reports highlight a potentially diverse but uncharacterized microbiome specific to individual sponge species, which opens up an opportunity to investigate this unique flora for novel antimicrobial compounds.

The current lack of information regarding the cultivable sponge-associated inhabitants of Hexactinellid sponges and their antimicrobial potential represents a knowledge gap in the current literature. Therefore, the aim of this study was to utilize novel media and pressure culture methods to improve recovery of hexactinellid-associated bacteria in the search for novel antimicrobial producers.

\section{METHODS}

\section{Sample collection}

Sponge samples were collected from the North East Atlantic deep-sea, as part of two different research programmes: the
NERC-funded DeepLinks Project in 2016 (RRS James Cook - JC136), and the Sensitive Ecosystem Assessment and ROV Exploration of Reef (SEAROVER) project in 2017 (Irish Light Vessel Granuaile - GRNL2017, RH17001), and again in 2019 (RV Celtic Explorer CE19015). Sample collection sites are displayed in Fig. S4 (available in the online version of this article) with sample co-ordinates and metadata displayed in Table S3. Both cruises conducted sampling of a wide range of deep-sea organisms. Sponges were collected by remotely operated vehicles (ROVs) and photographed in situ before removal (see Fig. 1).

On surfacing, sponges were transferred from the ROV into buckets containing in situ seawater and taken into the laboratory for processing. Sponge samples were photographed and a small tissue sample was taken for genetic analysis. The remaining sponge sample was then placed in a plastic zip-lock bag and frozen at $-20{ }^{\circ} \mathrm{C}$ for the remainder of the cruise. Upon return to land, frozen samples were transported in dry ice and maintained at $-80{ }^{\circ} \mathrm{C}$.

\section{Sponge identification}

Sponges were identified from the analysis of internal and external morphological features (i.e. body shape, type, size and arrangement of spicules) following the Systema Porifera 
classification system [25]. For spicule analysis, under sterile conditions using ethanol-washed and flame-sterilized scalpels, cuttings of approximately $1 \mathrm{~cm}^{3}$ were taken from the three regions on the sponge body, mesohyl, atria and the prostalia. Tissues were placed inside Eppendorf tubes $(2 \mathrm{ml})$, covered with $65 \%$ nitric acid and left for $2 \mathrm{~h}$ for spongin tissue to dissolve. The tubes were gently centrifuged at $600 \mathrm{~g}$ for 2 min. The supernatant was carefully discarded and the pellet containing spicules was re-suspended in water three times to wash all remaining acid. Spicules were then washed in $>95 \%$ ethanol twice before being left at room temperature for the ethanol to evaporate. Dry spicules were inspected under a compound light microscope and identified [25].

\section{Sample processing}

For isolation of bacteria, sponge samples were allowed to come to room temperature naturally. Sections of the sponge mesohyl were cut from the sponge using a sterile scalpel. Individual tissue segments $(\sim 10 \mathrm{~g})$ were then homogenized using a sterile mortar and pestle and transferred to a sterile $50 \mathrm{ml}$ falcon tube (Fisher Scientific). Large and un-degradable (spicular) debris was left to settle for $5 \mathrm{~min}$ and the remaining suspended homogenate was transferred to a new sterile $50 \mathrm{ml}$ falcon tube. The homogenate was then centrifuged (4696 $g$, $20 \mathrm{~min}$ ) to obtain a pellet. The pellet was then re-suspended in $2 \mathrm{ml}$ sterile PBS and $100 \mu \mathrm{l}$ was spread onto individual agar plates. To minimize the effects of repetitive freezing on the original sponge sample, as well as to aid replicability, all sponge segments were processed at the same time. Unused bacterial cell suspensions and sponge tissue segments were stored at $-20^{\circ} \mathrm{C}$ in natural seawater (NSW) $+50 \%$ glycerol for later use.

\section{Agar-based comparison of bacterial richness and abundance}

A range of solid-growth media was used for bacterial recovery. Abbreviations in the text and figures are as follows. MA: marine agar; MC: marine agar+carnitine hydrochloride $\left(0.2 \mathrm{~g} \mathrm{l}^{-1}\right)$; LB: LB agar; LC: LB agar+carnitine hydrochloride

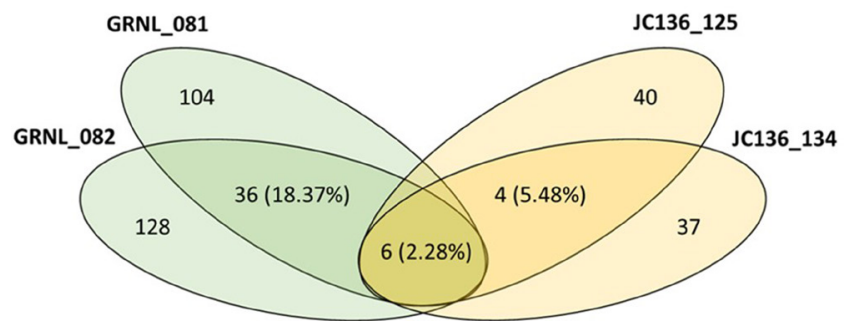

Fig. 3. Venn diagram of shared diversity between Hertwigia sp. replicates (in green) and Pheronema carpenteri replicates (in yellow). The number on the outer edges of the ellipses denotes the number of morphotypes for each individual replicate. The percentage number in the corresponding colour denotes the shared morphotypes between replicates of the same type. The central figure denotes the number of shared morphotypes between all Hertwigia sp. and P. carpenteri replicates as a whole. $\left(0.2 \mathrm{~g} \mathrm{l}^{-1}\right)$; RC: R2A agar+carnitine hydrochloride $\left(0.2 \mathrm{~g} \mathrm{l}^{-1}\right)$; OM: oatmeal agar; SYP-SW: starch-yeast-peptone-seawater agar [26]; ABC: PS medium [27]. A full list of media used is contained within the Supplementary Material. A bacterial cell suspension was spread evenly across agar plates. Where agar contained carnitine hydrochloride, $0.2 \mathrm{~g} \mathrm{l}^{-1}$ carnitine hydrochloride (Sigma-Aldrich) was added before autoclaving. Sponge spicule extract (SSE) was prepared as follows: $10 \mathrm{~g}$ sponge host tissue was homogenized with a sterilized mortar and pestle. Homogenate was extracted overnight in $50 \mathrm{ml}$ distilled $\mathrm{H}_{2} \mathrm{O}\left(\mathrm{dH}_{2} \mathrm{O}\right)$ and filtered-sterilized using a 0.22 $\mu \mathrm{m}$ filter. The cake remaining on filters was suspended in $50 \mathrm{ml} \mathrm{dH_{2 }}$ O, centrifuged at $138 \mathrm{~g}$ for $10 \mathrm{~min}$ and the pellet re-suspended in $20 \mathrm{ml} \mathrm{dH}_{2} \mathrm{O}$. SSE $\left(40 \mathrm{ml} \mathrm{l}^{-1}\right)$ was added to $1.5 \%$ agar, $33.3 \mathrm{~g} \mathrm{l}^{-1}$ Instant Ocean and $9.05 \mathrm{~g} \mathrm{l}^{-1} \mathrm{R} 2 \mathrm{~A}$ before autoclaving.

For each condition tested, three technical replicates were performed for each biological sponge replicate. For assessing the impact of different media on cultivation, all plates were incubated in the dark at $20^{\circ} \mathrm{C}$ for a total of 40 days, when all growth measurements were taken.

For assessing the effect of temperature on cultivation, four temperatures were initially assessed; $4{ }^{\circ} \mathrm{C}, 15^{\circ} \mathrm{C}$, ambient $\left(22-25^{\circ} \mathrm{C}\right)$ and $28^{\circ} \mathrm{C}$ on low nutrient $1 / 2 \mathrm{R} 2 \mathrm{~A}$ agar. Plates incubated at room temperature or above were incubated for 40 days and inspected bi-weekly. For lower incubation temperatures, the incubation period was 90 days, and cultures were monitored weekly.

For pressurized culture, agar plates spread with bacterial cell suspensions were placed into stainless steel containers $(650 \times 300$ $\mathrm{mm}$ ) (Southwestern Engineering). Gas mixtures were prepared at either 4 or $21 \% \mathrm{O}_{2}$ prior to being pumped into the chambers. Chambers were filled with gas mixtures until the desired pressure had been reached.

\section{Dilution to extinction - cell counting and dilution}

Bacterial cell suspensions from P. carpenteri (JC126_125/134) and Hertwigia sp. (GRNL_081/082) were prepared according to the steps outlined above. The approximate bacterial concentration was determined with the use of a haemocytometer. Cell suspensions were then diluted to approximately three to four cells per millilitre, and $333 \mu \mathrm{l}$ was added to each well of a 96-well plate, to give an approximate total of $\sim 1$ cell per well. A total of 288 wells were inoculated. Plates were incubated at $20^{\circ} \mathrm{C}$ for a period of 40 days.

\section{Antimicrobial screening using simultaneous antagonism}

Cell suspensions of the organism being screened against (the indicator) were prepared to specific $\mathrm{OD}_{600}$ readings for each species. Indicators used for preliminary screening were Micrococcus luteus $\left(\mathrm{OD}_{600}\right.$ 0.5), Staphylococcus aureus NCTC12493 $\left(\mathrm{OD}_{600} 0.5\right)$ and Escherichia coli $\mathrm{NCTC} 10418\left(\mathrm{OD}_{600} 0.4\right)$. Isolates obtained from bacterial culture were screened for antimicrobial activity using the simultaneous antagonism method [28]. 
(a)

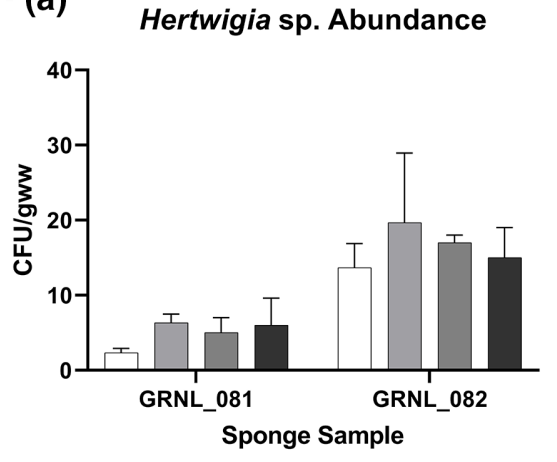

(c)

Pheronema carpenteri Abundance

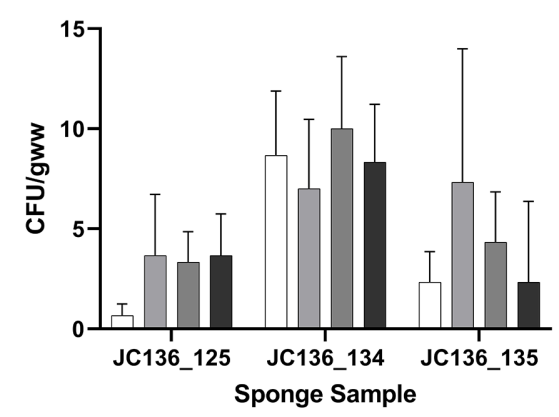

(b)

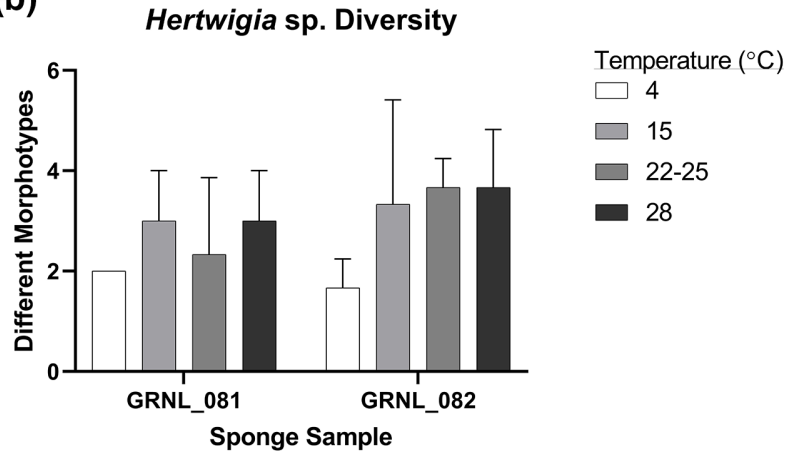

(d)

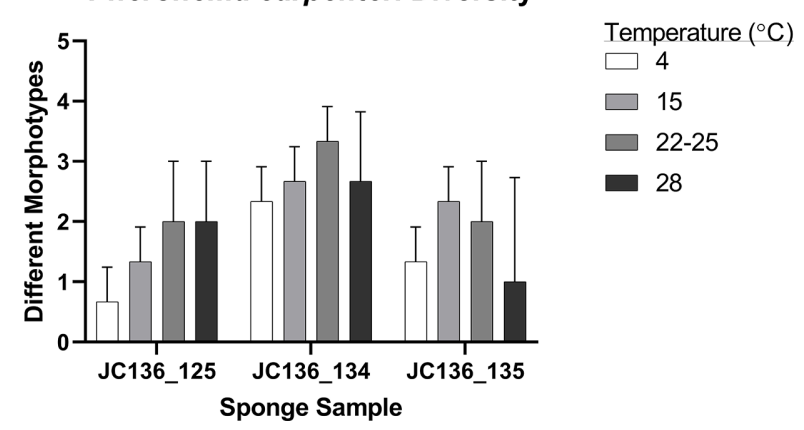

Fig. 4. Effect of temperature on the recovery of bacterial isolates across biological replicates of Hertwigia sp. and $P$. carpenteri. Effect of temperature on (a) bacterial abundance and (b) diversity in Hertwigia sp. Effect of temperature on (c) bacterial abundance and (d) diversity in P. carpenteri. All cultures were plated in triplicate. Bars: SD.

\section{DNA extraction and amplification}

Genomic DNA was extracted from isolates using the DNeasy Powersoil Kit (Qiagen) according to the manufacturer's conditions. DNA was quantified using a Qubit Fluorometer (Thermofisher Scientific). PCRs (50 $\mu$ l) were set up, consisting of $25 \mu \mathrm{l} 2 \times$ DreamTaq Green PCR Master Mix (Fisher Scientific), $2.5 \mu \mathrm{l}$ 27F 16S Primer (5'-3' AGAGTTTGATCATGGCTCA), $2.5 \mu \mathrm{l}$ 1492R 16S Primer (5'-3' TACGGTTACCTT GTTACGACTT) (Eurofins Genomics Standard Primers) [29-32], 5 $\mu$ l DNA Template (50-100 ng) and $15 \mu$ l nucleasefree water (Merck). PCR conditions for amplification of the $16 \mathrm{~S}$ rRNA gene consisted of an initial denaturation step of 5 min at $94^{\circ} \mathrm{C}$, followed by 30 cycles of $30 \mathrm{~s}$ at $94^{\circ} \mathrm{C}, 60 \mathrm{~s}$ at 52 ${ }^{\circ} \mathrm{C}$, $90 \mathrm{~s}$ at $72^{\circ} \mathrm{C}$ and a final extension step of $10 \mathrm{~min}$ at $72{ }^{\circ} \mathrm{C}$.

\section{Bacterial sequence classification and tree building}

Amplicons of the 16S rRNA gene were sequenced using Sanger Sequencing (LGC Genomics). The forward and reverse strands of the 16S rDNA gene were sequenced separately and trimmed to remove regions that had more than a $5 \%$ chance of per-base error. Forward and reverse sequences were then aligned to each other in order to provide a consensus sequence. Sequences were compared against the NCBI Nucleotide collection (nr/nt) database using the BLAST function in Geneious Prime v2020.2.2 with standard parameters.
A phylogenetic, neighbour-joining tree was reconstructed using the Tamura-Nei distance model [33]. Tree-building was performed in Geneious Prime using the Geneious Tree Builder tool with standard parameters. The tree was exported as Newick-format and uploaded to iToL (https://itol.embl. $\mathrm{de} /$ ) for visualization.

\section{RESULTS}

\section{Low-nutrient media recover highest bacterial abundance and diversity for $P$. carpenteri and Hertwigia sp.}

Preliminary optimization of bacterial culture was carried out for two species of deep-sea hexactinellid sponges using a range of solid growth media. Abundance counts were recorded as counts of individual colonies, irrespective of morphotype, while diversity counts record different morphotypes. The word morphotype here refers to bacterial colonies that were distinguishable using the naked eye. Each colony present on a particular agar was cross-referenced by searching for a colony of the same visible morphology on all other plates of that media type. Parameters including colour, size, border, opacity and profile were taken into account. It should also be noted that these reports of abundance and diversity refer explicitly to cultivability, and not to the overall microbial communities 
(a)

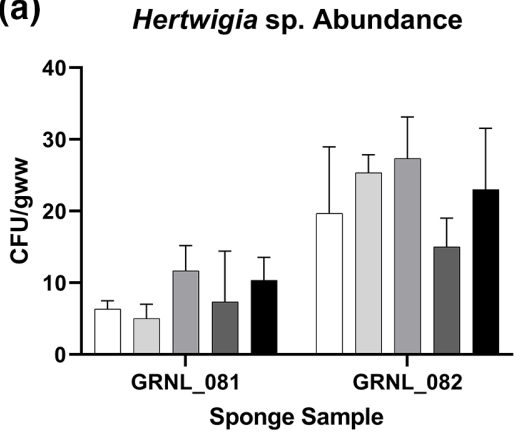

(c)

Pheronema carpenteri Abundance

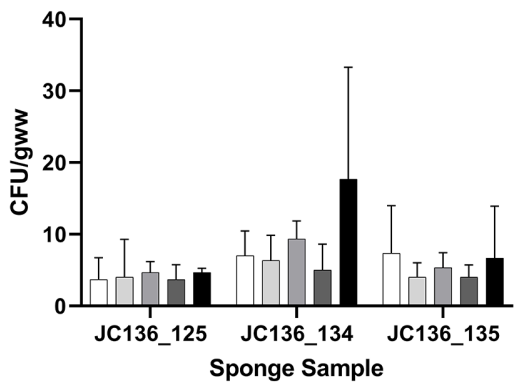

(b)

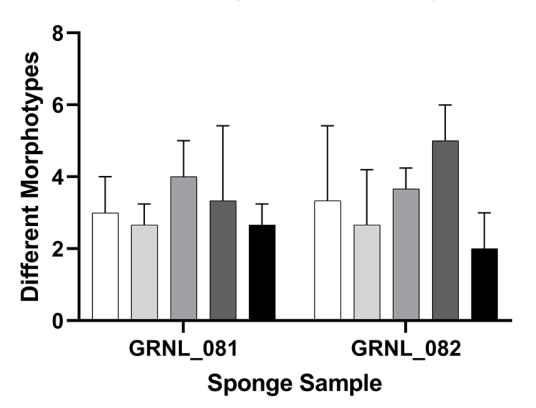

(d)

Pheronema carpenteri Diversity

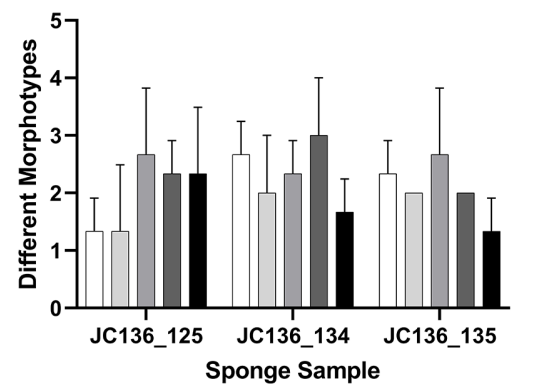

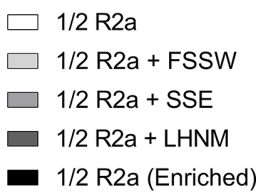

- 1/2 R2a (Enriched)

Fig. 5. Effect of media supplementation on recovery of bacterial isolates. Effect of supplementation on (a) bacterial abundance and (b) diversity in Hertwigia sp. Effect of supplementation on (c) bacterial abundance and (d) diversity in P. carpenteri. All cultures were plated in triplicate. Bars: SD. FSSW: filter-sterilized seawater; LNHM: low-nutrient heterotrophic media; SSE: sponge spicule extract.

of the sponges. For all media trialled, MA, MC and halfstrength marine agar ( $\left.1 \frac{2}{2} \mathrm{MA}\right)$ consistently yielded higher colony forming units per gram of wet weight of sponge (c.f.u. $\mathrm{gww}^{-1}$ ) across both sponge samples tested (Fig. 2a-e), while OM produced the lowest (Fig. 2a, d). Of the three, $1 / 2$ MA was the most successful in recovering bacteria from Hertwigia sp., with an average of 99.7 c.f.u. gww ${ }^{-1}$ (Fig. 2a), while MC was the most successful for $P$. carpenteri samples (Fig. 2d), averaging 9.3 c.f.u. gww $^{-1}$. Furthermore, the trend across all media types indicated an approximate 10 -fold greater recovery of bacteria from Hertwigia sp. samples compared to those from P. carpenteri. A significantly higher bacterial abundance was obtained from Hertwigia sp. across six of the 10 media used. Media that produced a significantly higher bacterial abundance were LB $(P=0.0077)$, RC $(P=0.0303), \mathrm{R} 2 \mathrm{a}(P=0.0024)$, $1 / 2$ MA $(P<0.0001)$, MA $(P<0.0001)$ and MC $(P<0.0001)$.

$\mathrm{RC}$ agar yielded the highest number of bacterial morphotypes for Hertwigia sp. (29.5 morphotypes gww $^{-1}$ ) while $1 / 2 \mathrm{MA}$ produced the highest number of bacterial morphotypes for P. carpenteri (16 morphotypes gww ${ }^{-1}$ ) (Fig. 2b, e). The correlation between the number of bacterial isolates and the number of bacterial morphotypes present on each growth medium after 40 days of incubation was quantified. For both sponges, there was a positive correlation between the abundance of bacteria and the diversity as measured by Pearson's correlation co-efficient $(r=0.4878, P$. carpenteri; $r=0.2253$, Hertwigia sp (Fig. 2c, f).

\section{P. carpenteri and Hertwigia sp. display low overlap in cultivable morphotypes}

Analysis of the percentage of bacterial morphotypes shared between the two Hertwigia sp. biological replicates (GRNL_081 and GRNL_082) (18.37\%) was higher than for P. carpenteri replicates (JC136_125 and JC136_134) (5.48\%). The number of morphotypes that were shared between sponge species was (2.28\%) (Fig. 3).

\section{Change in temperature produces different diversity and abundance of isolates from biological sponge replicates}

The total number of bacteria cultured across all temperatures was greater from Hertwigia sp. samples (255 isolates) compared to P. carpenteri samples (185 isolates) (Fig. 4a, c), though the difference was not significant [two-way ANOVA; $F(1.661,3.322)=0.4792, P=0.625]$. While intra-species differences were observed, incubating at $15^{\circ} \mathrm{C}$ produced the highest number of c.f.u. gww $^{-1}$ in three of five total sponge replicates, while the lowest was observed at $4{ }^{\circ} \mathrm{C}$ (Fig. 4a, c). The effect of temperature, however, was not uniform across biological replicates. A two-way ANOVA test examining 
(a)

\title{
Dilution-to-Extinction Growth
}

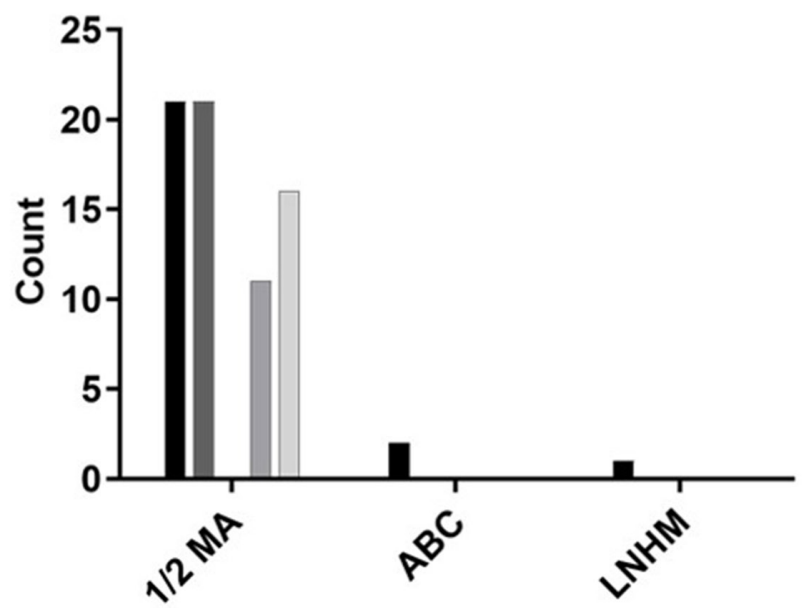

\author{
- P. carpenteri wells \\ $P$. carpenteri Isolates \\ Hertwigia. spp. wells \\ Hertwigia. spp. Isolates
}

(b)

\section{Liquid Media}

\begin{tabular}{|c|c|c|c|c|c|c|c|}
\hline \multicolumn{7}{|c|}{ Dilution to Extinction Culture Statistics } \\
\hline Sponge & $\begin{array}{c}\text { Growth-Positive } \\
\text { Wells }\end{array}$ & $\begin{array}{c}\text { Recoverable } \\
\text { Wells }\end{array}$ & Isolates & Singles & Doubles & Triples & Multiples \\
\hline P. carpenteri & $\begin{array}{c}24 \\
(8.33 \%)\end{array}$ & $\begin{array}{c}18 \\
(75 \%)\end{array}$ & 21 & $\begin{array}{c}16 \\
(88.89 \%)\end{array}$ & $\begin{array}{c}1 \\
(5.56 \%)\end{array}$ & $\begin{array}{c}1 \\
(5.56 \%)\end{array}$ & $\begin{array}{c}2 \\
(11.11 \%)\end{array}$ \\
\hline $\begin{array}{c}\text { Hertwigia } \\
\text { spp. }\end{array}$ & $\begin{array}{c}11 \\
(3.82 \%)\end{array}$ & $\begin{array}{c}9 \\
(81.82 \%)\end{array}$ & 16 & $\begin{array}{c}4 \\
(44.44 \%)\end{array}$ & $\begin{array}{c}3 \\
(33.33 \%)\end{array}$ & $\begin{array}{c}2 \\
(22.22 \%)\end{array}$ & $\begin{array}{c}5 \\
(55.56 \%)\end{array}$ \\
\hline
\end{tabular}

Fig. 6. (a) Growth statistics for bacteria grown in different media using the dilution to extinction method. (b) Table displaying statistics for the number of bacteria recovered from each treatment. Singles, Doubles and Triples refer to the number of wells from which one, two or three different morphotypes, respectively, were recovered when liquid from wells was plated onto solid media.

the effect of sponge individual on isolate recovery showed there was a significant difference between the two Hertwigia individuals and isolate recovery $[F(1,16)=47.28, P<0.0001]$. Tukey's post-hoc tests revealed that a greater number of isolates were recovered from GRNL_082 than GRNL_081, and for the temperatures $4{ }^{\circ} \mathrm{C}(P=0.0142), 15^{\circ} \mathrm{C}(P=0.004)$ and $22-25{ }^{\circ} \mathrm{C}(P=0.009)$ the two biological replicas were significantly different. The same tests were performed for $P$. carpenteri, showing again that there was an effect of sponge individual on isolate recovery $[F(2,24)=9.869, P=0.0007]$. Post-hoc tests showed that at onlyc $4{ }^{\circ} \mathrm{C}$ the recovery from sponges JC136_134 and JC136_125 was significantly different.

In terms of bacterial diversity, a higher number of bacterial morphotypes was observed from Hertwigia sp. samples at temperatures higher than $4^{\circ} \mathrm{C}$ (Fig. $4 \mathrm{~b}$ ). However, the difference in recovery between the $15^{\circ} \mathrm{C}, 22-25$ and $28^{\circ} \mathrm{C}$ groups was marginal. For $P$. carpenteri, the highest diversity was seen at the slightly lower temperature of $22-25^{\circ} \mathrm{C}$ and the lowest at $4{ }^{\circ} \mathrm{C}$ (Fig. $\left.4 \mathrm{~d}\right)$.

\section{Supplementing $1 / 2$ R2A did not significantly increase diversity or abundance of isolates recovered from Pheronema and Hertwigia sponges}

The effect of media supplementation on bacterial recovery was assessed for both species of sponge, to try and recover increased diversity of cultivable morphotypes. $1 / 2$ R2A medium was selected as a base medium for supplementation due to its relative success in recovery of isolates displaying antimicrobial activity in preliminary screens (see below). Supplements included either filter sterilized seawater (FSSW), low-nutrient heterotrophic media (LNHM) or SSE, with a fourth treatment including a $24 \mathrm{~h}$ enrichment incubation in LNHM prior to plating. The addition of SSE and the inclusion of a 24 h enrichment period produced a higher number of bacterial isolates in both biological replicates of Hertwigia sp. (Fig. 5a) and in two of three biological replicates for P. carpenteri (Fig. 5c), although it was not statistically significant. The addition of FSSW and LNHM reduced the number of c.f.u. recovered. For both sponges, a higher bacterial diversity was produced overall by the addition of SSE and LNHM. A twoway ANOVA was used to test the effect of media supplements on isolate recovery, revealing a non-significant effect $[\mathrm{F}(2.304$, 
Table 1. Isolates obtained from hexactinellid sponges that displayed antimicrobial activity in a simultaneous antagonism assay

\begin{tabular}{|c|c|c|c|c|c|}
\hline & & & \multicolumn{3}{|c|}{ Activity vs. } \\
\hline Parent sponge-Isolate ID & 16S rDNA identity based on closest database match & Isolation medium & M. luteus & MRSA & E. coli \\
\hline P. carpenteri-Ph28 & Bacillus altitudinis & LB & + & + & + \\
\hline P. carpenteri-RC14 & * & $\mathrm{RC}$ & + & + & - \\
\hline P. carpenteri-RC15 & * & $\mathrm{RC}$ & + & + & - \\
\hline P. carpenteri-RC17 & * & $\mathrm{RC}$ & + & + & - \\
\hline P. carpenteri-A11 & Streptomyces sp. & $\mathrm{RC}$ & + & + & + \\
\hline P. carpenteri-Ph7 & Streptomyces sp. & 1/2 MA (DTE) & + & + & - \\
\hline P. carpenteri-NS98 & Micrococcus antarcticus & $\mathrm{R} 2 \mathrm{~A}$ & + & - & - \\
\hline P. carpenteri-NS10M4 & Bacillus sp. & $1 / 2 \mathrm{MA}$ & - & - & + \\
\hline P. carpenteri-PB091 & Delftia acidovorans & $1 / 2 \mathrm{R} 2 \mathrm{~A}$ & + & + & - \\
\hline P. carpenteri-PB109 & * & $1 / 2 \mathrm{R} 2 \mathrm{~A}$ & + & + & - \\
\hline P. carpenteri-PE654 & * & $1 / 2 \mathrm{R} 2 \mathrm{~A}+\mathrm{SSE}$ & + & + & - \\
\hline P. carpenteri-PB-104 & Microbacterium paraoxydans & $1 / 2 \mathrm{R} 2 \mathrm{~A}$ & + & + & - \\
\hline P. carpenteri-PB-125 & Brevundimonas sp. & $1 / 2 \mathrm{R} 2 \mathrm{~A}$ & + & + & + \\
\hline P. carpenteri-PC-227 & Microbacterium maritypicum & $1 / 2 \mathrm{R} 2 \mathrm{~A}$ & + & + & + \\
\hline Hertwigia sp.-RC57 & * & $\mathrm{RC}$ & + & + & - \\
\hline Hertwigia sp.-SYP-1 & * & SYP & + & + & - \\
\hline Hertwigia sp.-SYP-2 & * & SYP & + & + & - \\
\hline Hertwigia sp.-RC230 & Delftia acidovorans & $1 / 2 \mathrm{R} 2 \mathrm{~A}$ & + & + & + \\
\hline Hertwigia sp.-RE707 & * & $1 / 2 \mathrm{R} 2 \mathrm{~A}+\mathrm{SSE}$ & + & + & + \\
\hline Hertwigia sp.-RI613 & * & $1 / 2 \mathrm{R} 2 \mathrm{~A}+\mathrm{FSSW}$ & + & + & - \\
\hline
\end{tabular}

M. luteus: Micrococcus luteus (lab strain); MRSA, Staphylococcus aureus NCTC 12493; E. coli, Escherichia coli NCTC 10418. Isolation media abbreviations as previously described.

*Isolates with low-level activity were not identified using 16 S rRNA gene sequencing.

$23.04)=2.617, P=0.088]$. Differences were observed between Hertwigia sp. individuals $[F(1,20)=49.64, P<0.0001]$ but not for $P$. carpenteri individuals $[F(2,30)=3.328, P=0.049]$. Bacterial diversity was, however, reduced by the addition of FSSW and by the inclusion of an enrichment stage. Again, there was no effect on the number of morphotypes observed following supplementation of $1 \frac{1}{2} \mathrm{R} 2 \mathrm{~A}[F(4,30)=1.845, P=0.146]$.

\section{Dilution to extinction culture produces more bacterial isolates from $P$. carpenteri than from Hertwigia sp}

Bacteria were grown from Hertwigia sp. (GRNL_081) and $P$. carpenteri (JC136_125) samples using a dilution to extinction (DTE) method $[34,35]$. Cell suspensions were diluted to approximately 3-4 cells $\mathrm{ml}^{-1}$, inoculated into individual wells of 96-well plates to give an approximate total of $\sim 1$ cell per well, and incubated for 40 days.

For $P$. carpenteri, 21 isolates were recovered on $1 / 2 \mathrm{MA}$, equal to the number of growth-positive wells (Fig. 6a). For Hertwigia sp., 16 isolates were recovered, higher than the number of growth-positive wells observed (Fig. 6a). For both sponges, several morphotypes were recovered from some individual wells, indicating mixed cultures (Fig. 6b). No bacteria were recovered on solid media from well-cultures of $\mathrm{ABC}$ media or LNHM. A higher number of growth-positive wells, as well as a higher number of bacterial isolates were obtained from P. carpenteri (Fig. 6a). A total of 37 bacterial isolates were cultured.

The percentage cultivability of each sponge (based on the Button et al. [34] and Connon and Giovannoni [35] methodology), was predicted to be $1.039 \%$ for $P$. carpenteri and $0.097 \%$ for Hertwigia sp. The number of wells containing pure cultures was predicted to be $34.66 \%$ for $P$. carpenteri. The actual percentage of wells containing pure cultures, as measured by counting morphotypes cultured on solid media, was $16.67 \%$. The number of wells containing pure cultures was predicted to be $10.78 \%$ for Hertwigia sp., though the percentage of actual recoverable morphotypes was $4.17 \%$. Cell 


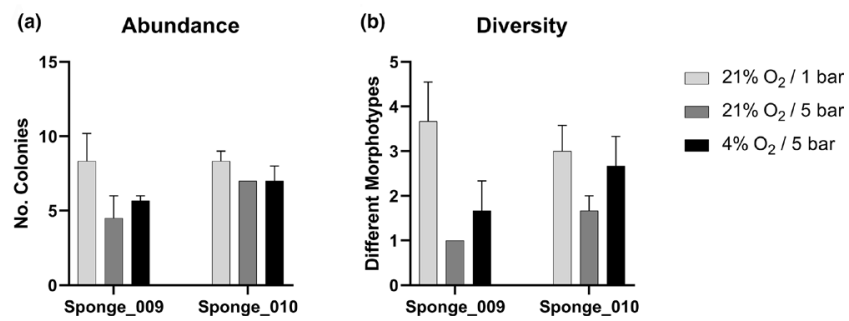

Fig. 7. Abundance and diversity measurements for bacteria recovered from $P$. carpenteri and cultured under altered atmospheric conditions. (a) Abundance counts. (b) Diversity counts. Bars: SE across three technical replicates.

counting of a bacterial suspension from each sponge using a haemocytometer suggested there to be around twice as many cells present in the $P$. carpenteri suspension, $\sim 2.25 \times 10^{7}$ cells $\mathrm{ml}^{-1}$, compared to $\sim 1.2 \times 10^{7}$ cells $\mathrm{ml}^{-1}$ for Hertwigia sp.

\section{Culturing under altered atmospheric pressure/ $\mathbf{O}_{2}$ reveals additional bacterial genera from $\boldsymbol{P}$. carpenteri}

Further bacterial cultivation was carried out for two separate sponges of $P$. carpenteri (hereafter named Sponge_009 and Sponge_010) collected from a later cruise (Table S3). Further work was carried out on $P$. carpenteri given that a higher number of isolates recovered under a normal atmosphere from this sponge displayed antimicrobial activity than was observed for Hertwigia sp. (Table 1, below). Increased pressures were generated with the use of stainless steel chambers (Fig. S5), with the pressure limits determined by the capacity of the chambers used. Gas mixtures were prepared at either 4 or $21 \% \mathrm{O}_{2}$ prior to being pumped into the chambers. Sealed chambers were filled with gas mixtures until the desired pressure had been reached. The pressure simulated in this study ( 5 bar) was equivalent to 4.93 atmospheres, which is representative of an ocean depth of almost $50 \mathrm{~m}$.

Culturing $P$. carpenteri samples at increased pressure $(21 \%$ $\mathrm{O}_{2} / 5$ bar) resulted in either a similar or reduced bacterial abundance when compared to those grown under the control conditions $\left(21 \% \mathrm{O}_{2} / 1\right.$ bar) (Fig. $\left.7 \mathrm{a}\right)$. A similar result was also seen for those samples cultured at 5 bar combined with a lower oxygen concentration (4\%). A significant reduction in bacterial diversity was also seen for Sponge_009 samples incubated at $21 \% \mathrm{O}_{2} / 5$ bar, when compared to the control group using a two-way ANOVA $(P=0.0331)$ (Fig. $7 \mathrm{~b})$. A reduction was also observed for those incubated in the lower oxygen concentration, but this was not significant. This indicates that, in these experiments, increased pressure did not improve the abundance or diversity yields from $P$. carpenteri cultured on R2A medium over that of the control conditions.

Bacteria from each environmental condition were subcultured onto solid media in non-pressured conditions and genomic DNA was extracted from each individual morphotype cultured. Sequencing, quality-trimming and aligning of the forward and reverse 16S rRNA gene sequence resulted in data for 39 isolates, as shown in the histograms for sequence length, query cover (\%) and identical sites (\%) of all BLASTN queries (Figs S1-S3).

The top BLASTN hits for all 16S rDNA sequences were filtered to those that matched with $100 \%$ query cover and a $<97 \%$ site identity. Filtering sequences in this way revealed the presence of a single $16 \mathrm{~S}$ rDNA sequence that may represent a potentially novel Bacillus species. The sequence was from an isolate recovered at $21 \% \mathrm{O}_{2} /$ atmospheric pressure and matched most closely to Bacillus sp. ITP29 with an identical site percentage of $96.6 \%$. The filtering cutoffs were relaxed to also include those that had an identical site percentage of $<99 \%$, in accordance with updated operational taxonomic unit (OTU) clustering recommendations [36]. By including all 16S rDNA sequences that were divergent from those in the NCBI database by $>1 \%$, rather than by $>3 \%$, the number in the filtered list increased from one to nine, as only one sequence had an identical site match of $<97 \%$. The nine $16 \mathrm{~S}$ rDNA sequences that had an identical site match of $<99 \%$ matched to sequences related to Psychrobacter piscatorii, Pseudomonas sp., Erythrobacter sp., Dermacoccus nishinomiyaensis, Bacillus sp. and 'Uncultured bacterium clone Md-9.

Of the 39 isolates, 15 were obtained from Sponge_009, whereas 24 were obtained from Sponge_010. All 15 sequences from Sponge_009 had unique BLASTN identities, 13 of which $(86.7 \%)$ were unique to Sponge_009. A total of 18 of the 24 sequences from Sponge_010 had unique BLASTN identities, 16 of which $(88.9 \%)$ were unique to Sponge_010. Two sequences from each sponge had a shared BLASTN identity. Of the 31 unique BLASTN identities, 29 (93.5\%) of these were unique to a particular sponge.

A neighbour-joining tree of all 39 16S rDNA sequences (alignment length $1621 \mathrm{nt}$ ) from each sample treatment revealed that they did not cluster together at the species level, indicating that isolates from each sample treatment were not more closely related (Fig. 8).

A total of 39 different morphotypes were recovered from the $P$. carpenteri samples, belonging to 13 genera (Fig. 9a) within the phyla Proteobacteria, Actinobacteria and Firmicutes (Fig. 9b). Of these, 16 (41\%) were from $21 \% \mathrm{O}_{2} / 1.01$ bar, ten (25.6\%) from $21 \% \mathrm{O}_{2} / 5$ bar, and $13(33.3 \%)$ from $4 \% \mathrm{O}_{2} / 5$ bar. The most common genus recovered was Psychrobacter (25.6\%), a proteobacterium present in all three sample types (Fig. 9c). Bacteria from all three phyla were recovered from $21 \% \mathrm{O}_{2} / 1.01$ bar and $21 \% \mathrm{O}_{2} / 5$ bar, but no Firmicutes were identified in the $4 \% \mathrm{O}_{2} / 5$ bar (Fig. $9 \mathrm{~d}$ ).

While increased pressure reduced overall bacterial abundance, it appeared to promote the recovery of certain genera that were not cultured under the control conditions. An isolate of the genus Microbacterium genus was found in the samples incubated at $21 \% \mathrm{O}_{2} / 5$ bar but not at $21 \% \mathrm{O}_{2} / 1.01$ bar or at $4 \% \mathrm{O}_{2} / 5 \mathrm{bar}$, indicating that a combination of higher oxygen and pressure may favour the recovery of this specific genus. Dermacoccus, Kocuria and Brevibacterium were only cultured 


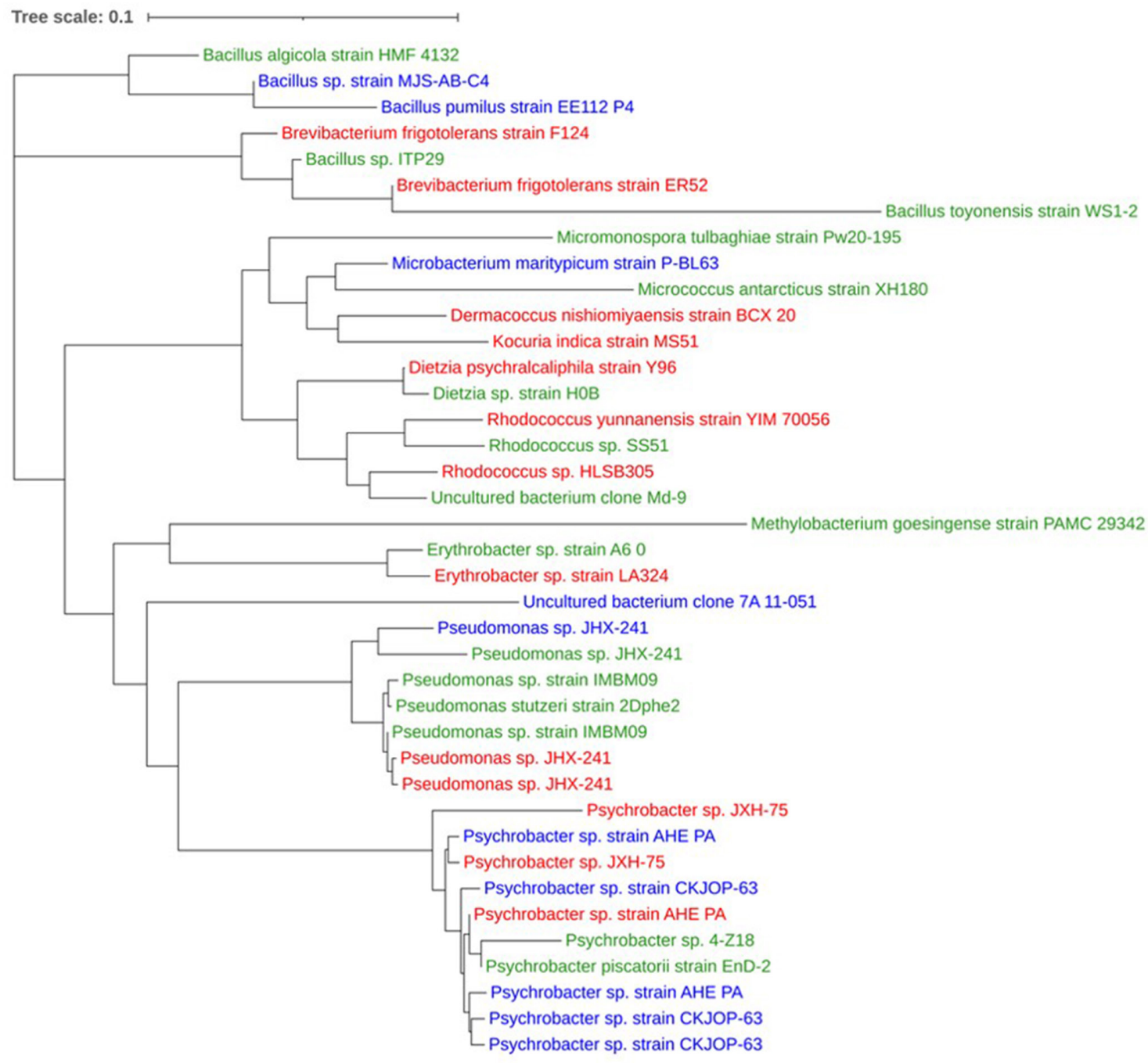

Fig. 8. Neighbour-joining tree of $16 \mathrm{~S}$ rDNA sequences obtained from bacterial isolates cultured from P. carpenteri. Taxonomic IDs represent the top BLASTN hit for each sequence. Colours represent the treatment at which each isolate was recovered. Green: $21 \%$ $\mathrm{O}_{2} / 1.01$ bar; blue: $21 \% \mathrm{O}_{2} / 5$ bar; red: $4 \% \mathrm{O}_{2} / 5$ bar.

on R2A at $4 \% \mathrm{O}_{2} / 5$ bar, while Micrococcus, Micromonospora and Methylobacterium were only cultured at $21 \% \mathrm{O}_{2} / 1.01$ bar (Fig. 9d), further evidencing the need to implement different environmental factors when attempting to improve recovery of sponge bacterial diversity.

\section{Bacteria from hexactinellid sponges display antimicrobial activity against clinically relevant bacterial strains}

A total of 1115 bacterial isolates were screened for antimicrobial activity using a simultaneous antagonism assay. Briefly, a confluent lawn of an indicator organism was spread across an agar plate and 'spotted' with sponge isolates. The plates were incubated and assessed visually for a 'zone of inhibition' around each sponge isolate, with a total of 621 (55.7\%) isolates from Hertwigia sp. and 494 (44.3\%) from $P$. carpenteri. The potential screening of duplicate strains was a possibility given isolates were obtained at different stages and via different methods. Each isolate was initially screened for antimicrobial activity against the three test bacteria $M$. luteus, S. aureus and E. coli (Table 1). S. aureus and E. coli were chosen for their clinical relevance as well as to represent both Gram-positive and Gram-negative bacteria. M. luteus in particular was chosen due to its relative susceptibility to antimicrobials, thought to be a reflection of its small genome and resulting lack of certain resistance proteins found in other Actinobacteria [37]. M. luteus was therefore considered a good target, or 'wide net', for first-pass antimicrobial detection. Of the 20 isolates that displayed antimicrobial activity, 18 (90\%) were active against both Gram-positive organisms, while the $19^{\text {th }}$ isolate, Micrococcus antarcticus, showed activity against M. luteus only. Six isolates (30\%) were active against both Gram-positive and Gram-negative organisms, with those that were identified coming from all three phyla recovered 
(a)

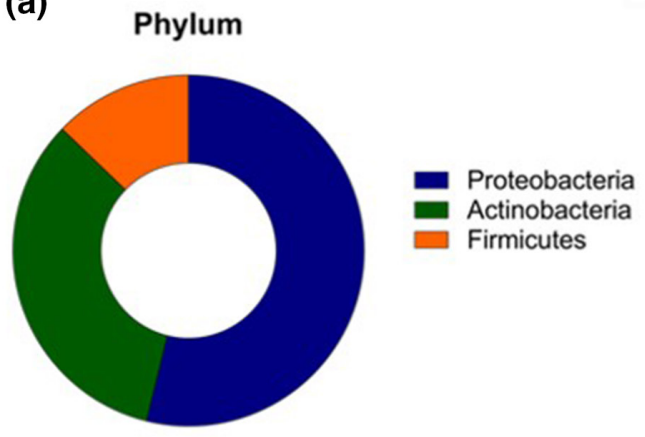

(b)

Treatment Phylogeny (Phylum)

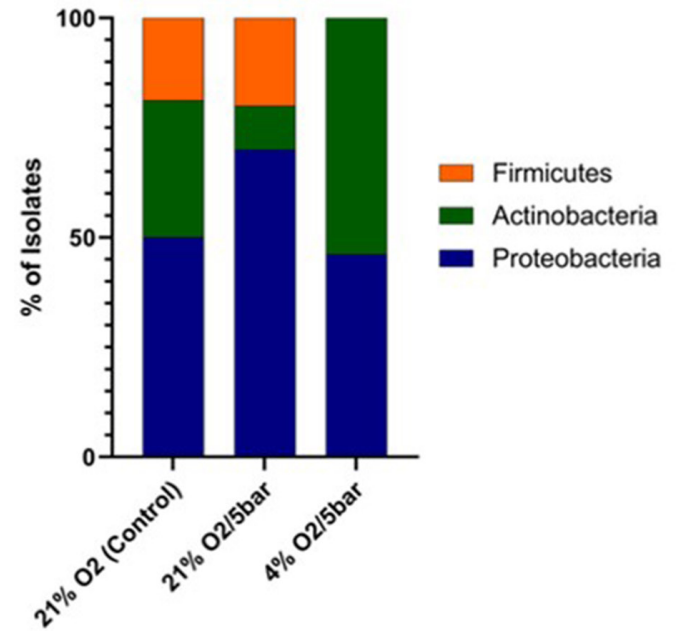

(b)

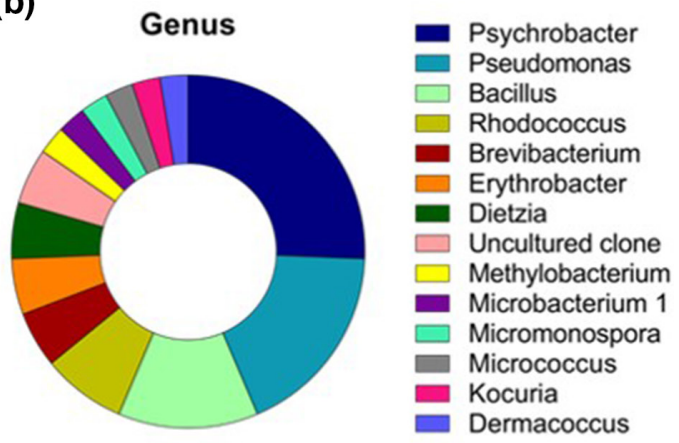

(c)

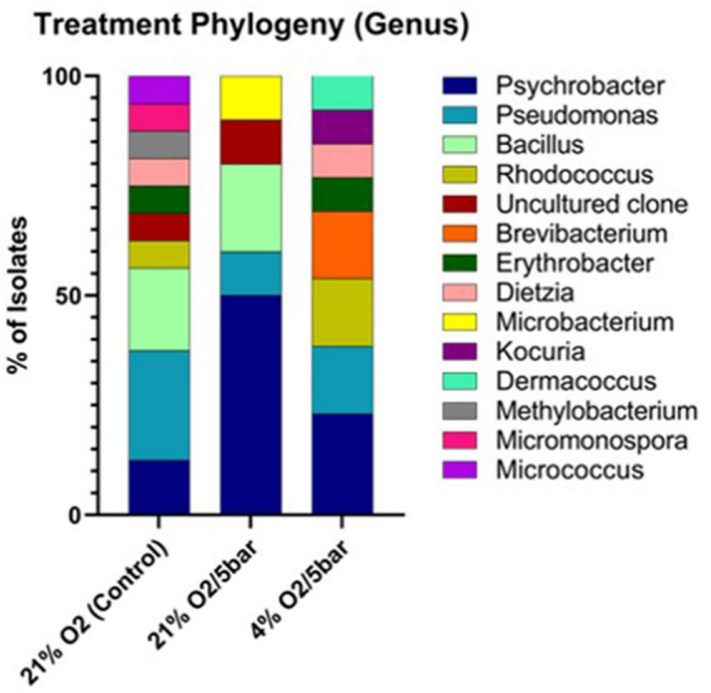

Fig. 9. (a) Phylum- and (b) genus-level distribution of all P. carpenteri isolates sequenced. (c) Phylum- and (d) genus-level distribution of isolates recovered, split by sample treatment.

(Actinobacteria, Proteobacteria and Firmicutes), while only one isolate $(5 \%)$ was solely active against $E$. coli.

\section{DISCUSSION}

\section{Culture using solid media and community dissimilarity}

Most studies investigating bacteria with antimicrobial activity from sponge microenvironments have focused on those sponges collected from shallow waters (<200 m deep) and those from the class Demospongiae. To optimize the culture of bacteria from two previously uncharacterized species of hexactinellid sponge, bacteria were cultured on a range of solid-growth media, representing the first culture-based microbial analysis of these two sponges. The number of c.f.u. and the number of distinct morphotypes (i.e. abundance and diversity) were also compared between isolates obtained from P. carpenteri and Hertwigia sp. In general, this revealed a higher abundance of isolates from Hertwigia sp. and the positive impact of lower-nutrient media designed to mimic the marine environment, across both sponge species. The inclusion of seawater in culture media (SYP-SW), whilst resulting in low bacterial abundance, did produce a relatively high number of bacterial morphotypes, particularly in the case of Hertwigia. The use of carnitine, a substrate for which sponge bacteria have previously been shown to display metabolic specialization [38], did not appear to significantly increase the number of bacterial c.f.u. or morphotypes.

Maximizing the chance that recovered bacterial isolates are derived from the marine/sponge environment attempts to reduce the chance for re-discovery of previously characterized antimicrobials by taking advantage of the increased species and functional richness associated with deeper waters $[39,40]$ and the number of marine natural products that have been discovered from the marine environment in recent years $[7,8]$. It is also important for studies seeking to screen recovered isolates for antimicrobial activity to consider 
which media produce the highest number of distinct bacterial morphotypes (i.e. diversity), rather than just abundance - a higher number of individual morphotypes provides a higher number that can be screened. It should be noted that whilst two isolates display similar morphologies, this does not mean that they will produce the same profile of secondary metabolites. Distinguishing colonies based on visual morphology attempts to provide an early, simple de-replication step in the process of identifying potentially novel antimicrobial candidates. However, this is limited by the fact that strains may display different morphologies when using different culture media, and that different bacteria may display highly similar morphologies that may be indistinguishable with the naked eye.

These observations provide an initial reassurance that the bacteria cultured are more likely to be those present in the marine environment, rather than the result of terrestrial contamination. Whether the bacteria cultured are truly 'sponge-associated' as opposed to being just from the marine environment in general was not investigated, and is unknowable without further investigation of metabolic and/or genetic specialization. This indication was further explored by the molecular characterization of isolates obtained from culture at altered atmospheric pressure, as will be discussed later.

The use of solid growth media resulted in a ten-fold increase in the number of colonies recovered from Hertwigia sp., although a similar increase was not observed for diversity, suggesting the Hertwigia sp. microbiota is dominated by either one or a small number of bacterial species that cannot be cultured. Cell counting techniques used in DTE experiments indicated there to be around twice as many cells present in the $P$. carpenteri suspension. Whilst cell counting techniques using only a haemocytometer are rudimentary, it does perhaps suggest the $P$. carpenteri sponge not only has a higher bacterial density but also a higher number of constituents that were either 'uncultivable' under the conditions applied, or perhaps unviable. Use of DTE experiments indicated that Hertwigia species have a much lower microbiome cultivability $(0.097 \%)$ than $P$. carpenteri $(1.039 \%)$. The formula for calculating percentage cultivability of bacteria devised by Button et al. [34] has since been updated to include information concerning the relative abundance of particular species within bacterial suspensions [14]. Culture of bacteria here by DTE would benefit from a $16 \mathrm{~S}$ rRNA taxonomic survey of the host microbiota, in order to provide this information.

Another initial indication of the community dissimilarity of each sponge species is the markedly low overlap between shared morphotypes [six (2.26\%) of 269 isolates]. Whilst this observation is limited by the small number of isolates obtained from $P$. carpenteri, it is supported by the fact that $87 \%$ of the $16 \mathrm{~S}$ rDNA sequences obtained from P. carpenteri had BLASTN identities that were found only a particular sponge replicate. It also appears that the different media used herein revealed distinct groups of bacterial morphotypes. This was noted in visual observations and is also highlighted by the lack in correlation between an increase in abundance and diversity. The increase in number of bacterial colonies recovered did not lead to a significant increase in a specific morphotype, with the increase being made up of representatives of numerous morphotypes.

\section{Comparison between biological replicates}

Due to the lack of information available on the hexactinellid microbiota, it is unknown how much variation exists between biological replicates of the same species. Perhaps the most extensive overview of the sponge microbiota to date included fewer than five biological replicates for the majority of species analysed [41]. It is interesting to note than even for species for which a high number of biological replicates was provided, there was still a high degree of variation in community dissimilarity as determined by $16 \mathrm{~S}$ rDNA sequence profiling [41]. In our efforts to observe the effects of isolation media, temperature and supplementation on culturing effects, we observed significant differences between biological samples belonging to the same species. In this study, sponge samples were classified as biological replicates if belonging to the same species and if they were retrieved from the same sampling event and depth. This attempts to control the effect that depth, a proxy for temperature and pressure, may have on the recoverability of sponge-associated bacteria. The $P$. carpenteri sponges JC136_125 and 136 were both sampled from the same location at $1051 \mathrm{~m}$ depth, whereas the two Hertwigia sp. sponges were sampled at 2175 m (GRNL_82) and $2227 \mathrm{~m}$ (GRNL_81) depth (Fig. S3).

The most comprehensive analysis of the hexactinellid microbiota to date included three or four replicates of each species from 770 to $4160 \mathrm{~m}$ depth [22], reporting that the relative abundance of each taxon varied more widely between biological replicates of hexactinellid sponges than for demosponges. Members of the genera Hertwigia and Pheronema were absent from the Steinert study. Using the amplicon sequence variant (ASV) technique of classification [42], a greater dissimilarity in alpha-diversity was also observed between 33 replicates of the hexactinellid Vazella pourtalesii, compared to the microbiome of surrounding seawater and sediment, at ASV and phylum level [24]. It is therefore relevant to consider the differences in community composition between biological replicates of the same host species, particularly for those that have not been previously investigated. It appears from the preliminary investigation conducted here that cultivable differences are more pronounced between sponge species than for replicates of the same sponge species. Further in-depth $16 \mathrm{~S}$ rRNA gene or metagenomic community profiling would be recommended to fully explore these inter- and intra-sponge differences.

\section{Dilution-to-extinction culture}

Bacteria from Hertwigia sp. and P. carpenteri were cultivated using the DTE method. Whilst the use of $1 / 2$ MA produced colonies in 11/96 and 24/96 wells for Hertwigia sp. and P. carpenteri, respectively, the use of $\mathrm{ABC}$ and LNHM produced only a small number of colonies for $P$. carpenteri and none for Hertwigia sp. LNHM [43] and sterilized seawater [35] 
have previously been used for the cultivation of isolates from marine water. Given the success of $\mathrm{ABC}$ media in improving the diversity of bacteria recovered on solid media, it is surprising that such a low number were produced using DTE in the current study. A theoretical outcome of using DTE is that wells are more likely to contain members of the most highly abundant species present in the original sample. The observation that a lower number of isolates were obtained from Hertwigia sp. may support the concept that the microbiota is dominated by one or several 'uncultivable' species. However, this does not provide an explanation for why such a low number of isolates were produced from $P$. carpenteri when using ABC and LNHM. The calculated cultivability value was much lower for Hertwigia sp.

\section{Culture at increased atmospheric pressure}

Bacteria from the phyla Proteobacteria, Actinobacteria and Firmicutes were recovered from $P$. carpenteri samples cultivated under increased atmospheric pressure, at $21 \% \mathrm{O}_{2} / 5$ bar and at $21 \% \mathrm{O}_{2} / 1$ bar. Interestingly, the use of $4 \% \mathrm{O}_{2} / 5$ bar prevented the growth of Firmicutes. The addition of pressure to culture conditions appeared to increase the overall percentage of Proteobacteria isolates. The control group $\left(21 \% \mathrm{O}_{2}\right)$ resulted in the highest abundance and diversity recovered, while lowering the $\mathrm{O}_{2}$ to 4\% resulted in no Firmicutes being recovered but increased the percentage of Actinobacteria isolates. Bacteria cultured under the same atmospheric pressure $/ \mathrm{O}_{2}$ did not appear to be more closely related, or cluster together in terms of $16 \mathrm{~S}$ rRNA gene similarity. There were, however, species that were unique to each atmospheric condition.

The addition of pressure $(21 \% \mathrm{O} / 5 \mathrm{bar})$ reduced the overall number of bacteria cultured, but produced isolates belonging to Microbacterium and an 'uncultured bacterial clone'. Isolates grown under a low- $\mathrm{O}_{2}$, pressurized environment $\left(4 \% \mathrm{O}_{2} / 5\right.$ bar) included members of Dermacoccus, Kocuria and Brevibacterium.

The lack of data from $4 \% \mathrm{O}_{2}$ at atmospheric pressure in this study prevents a more comprehensive analysis into whether certain isolates were selectively cultured by the combination of low $\mathrm{O}_{2}$ and pressure. The ability of all isolates to grow in non-pressurized environments once sub-cultured, however, demonstrates that none of them require pressure for their growth. It may also be that the combination of pressure and low $\mathrm{O}_{2}$ concentration prevented the growth of competing bacteria in the first instance. Isolates that did not require pressure for their growth may also have grown more favourably under pressurized conditions. Isolates belonging to the psychrotolerant Psychrobacter [44] were the most common across all sample treatments.

The sponges used in this study were obtained from depths ranging between 1051 and $2228 \mathrm{~m}$, which is equivalent to $~ 105-$ 223 atmospheres of pressure. The pressure simulated in this study ( 5 bar) was equivalent to 4.93 atmospheres, which is representative of a depth of almost $50 \mathrm{~m}$. Previous work detailing the range of cellular processes affected by pressure suggest that essential biological processes (in E. coli) are not prevented until pressures much higher than this [45]. Therefore, it is assumed that many bacterial species associated with $P$. carpenteri and Hertwigia sp. may be cultivable at much higher pressures than those used in this study. Further work in assessing the impact of higher pressure on the cultivation of sponge-associated bacteria, and their ability to thrive and survive at such pressures would be of benefit in exploring this, though the practicalities of doing such work may represent a significant hurdle. The pressures at which bacteria were grown here were determined by the pressure capacity of the containers used.

\section{Antimicrobial screening}

A total of 20 (1.79\%) of the 1115 isolates screened displayed antimicrobial activity. Previous reports of antimicrobial screening vary with respect to sample and methodology. Previous studies from sponges have reported hit rates of $8.4-41 \%$ without dereplication strategies [46-48]. Previous studies in soil and wastewater have reported hit rates of 1.3-42.4\% [49, 50]. Highthroughput studies screening small-molecule libraries report a hit rate of $\sim 0.5 \%$ [51]. Of the 20 isolates that displayed antimicrobial activity, 16 were recovered from $P$. carpenteri. This is perhaps surprising considering the much lower number of isolates obtained from this sponge, compared to the Hertwigia sp. samples. The prevalence of active isolates was used to select a sponge for bacterial culture at increased pressure, but it remains to be seen whether the $P$. carpenteri microbiota contains more bacteria that produce antimicrobial compounds in vitro. Observations about the potential composition of the $P$. carpenteri microbiota provided by DTE culture may become relevant if bioactive bacteria cultivated from P. carpenteri are found to include members of the rare biosphere. The majority of isolates that displayed antimicrobial activity did so against Grampositive organisms, while several were also active against $E$. coli NCTC10418. The need for the discovery of novel antimicrobial agents active against Gram-negative organisms is of particular importance, given the lack of available agents effective against drug-resistant members of this group [52]. Isolates that appeared to display inhibitory activity towards E. coli NCTC10418 were recovered from both sponge species studied here, indicating the value in continued investigation of the bioactive potential of their associated microbiota.

\section{CONCLUSIONS}

An evaluation of bacterial culture-based methods was carried out for two previously uncharacterized species of the hexactinellid sponge, revealing a higher number of cultivable isolates from Hertwigia sp. and a higher proportion of bioactive isolates from $P$. carpenteri. The use of elevated atmospheric pressure was demonstrated to have an impact on the bacterial genera that were capable of being recovered. Isolates were screened for antimicrobial activity, producing several isolates of interest, active against Gram-positive and Gram-negative bacteria. These have been prioritized for downstream analysis. This study constitutes the first exploration of the diversity and antimicrobial potential of the microbiota from P. carpenteri and Hertwigia sp. sponges, as well as the use of pressure in culturing 
bacteria from such samples. It appears that the cultivation of isolates with antimicrobial potential from $P$. carpenter $i$ is more likely than from Hertwigia sp. However, there also exists intraspecies dissimilarity between cultivable bacteria from both sponges. Further molecular, microbiome-level investigation would be recommended to examine trends in detail. Overall, the isolates obtained herein provide a promising avenue for further investigation and indicate that Pheronema sponges are promising targets for the isolation of novel antimicrobial candidates. The 16S rRNA gene sequences generated by this study were submitted to GenBank under accession numbers MZ723441 to MZ723479. A full list of accession numbers can be found in Table S4.

\section{Funding information}

This work was made possible by funding from the Society for Applied Microbiology in the form of a PhD studentship to M.K. P.H.B. was supported by a PhD studentship from the School of Biological and Marine Sciences, University of Plymouth.

\section{Conflicts of interest}

The authors declare that there are no conflicts of interest.

\section{References}

1. O'Neill J. Tackling Drug-Resistant Infections Globally: Final Report and Recommendations. 2016

2. Lewis K. New approaches to antimicrobial discovery. Biochem Pharmacol 2017:134:87-98.

3. Ling LL, Schneider T, Peoples AJ, Spoering AL, Engels I, et al. A new antibiotic kills pathogens without detectable resistance. Nature 2015:517:455-459.

4. Love GD, Grosjean E, Stalvies C, Fike DA, Grotzinger JP, et al. Fossil steroids record the appearance of Demospongiae during the Cryogenian period. Nature 2009;457:718-721.

5. Yin Z, Zhu M, Davidson EH, Bottjer DJ, Zhao F, et al. Sponge grade body fossil with cellular resolution dating $60 \mathrm{Myr}$ before the Cambrian. Proc Natl Acad Sci U S A 2015;112:E1453-60.

6. Weisz JB, Lindquist N, Martens CS. Do associated microbial abundances impact marine demosponge pumping rates and tissue densities? Oecologia 2008;155:367-376.

7. Blunt JW, Copp BR, Keyzers RA, Munro MHG, Prinsep MR. Marine natural products. Nat Prod Rep 2017:34:235-294.

8. Blunt JW, Carroll AR, Copp BR, Davis RA, Keyzers RA, et al. Marine natural products. Nat Prod Rep 2018;35:8-53.

9. Webster NS, Hill RT. The culturable microbial community of the Great Barrier Reef sponge Rhopaloeides odorabile is dominated by an $\alpha$-Proteobacterium. Marine Biology 2001;138:843-851.

10. Esteves AIS, Hardoim CCP, Xavier JR, Gonçalves JMS, Costa R. Molecular richness and biotechnological potential of bacteria cultured from Irciniidae sponges in the north-east Atlantic. FEMS Microbiol Ecol 2013;85:519-536.

11. Montalvo NF, Davis J, Vicente J, Pittiglio R, Ravel J, et al. Integration of culture-based and molecular analysis of a complex spongeassociated bacterial community. PLoS One 2014:9:e90517.

12. Bergman 0 , Haber M, Mayzel B, Anderson MA, Shpigel M, et al. Marine-based cultivation of diacarnus sponges and the bacterial community composition of wild and maricultured sponges and their larvae. Mar Biotechnol 2011;13:1169-1182.

13. Staley JT, Konopka A. Measurement of in situ activities of nonphotosynthetic microorganisms in aquatic and terrestrial habitats. Annu Rev Microbiol 1985;39:321-346.

14. Henson MW, Lanclos VC, Pitre DM, Weckhorst JL, Lucchesi AM, et al. Expanding the diversity of bacterioplankton isolates and modeling isolation efficacy with large-scale dilution-to-extinction cultivation. Appl Environ Microbiol 2020;86:e00943-20.

15. Steinert G, Whitfield S, Taylor MW, Thoms C, Schupp PJ. Application of diffusion growth chambers for the cultivation of marine sponge-associated bacteria. Mar Biotechnol 2014:16:594-603.

16. Sipkema D, Schippers K, Maalcke WJ, Yang Y, Salim S, et al. Multiple approaches to enhance the cultivability of bacteria associated with the marine sponge Haliclona (gellius) sp. Appl Environ Microbiol 2011;77:2130-2140.

17. Tamburini $C$, Canals $M$, Durrieu de Madron X, Houpert L, Lefèvre D, et al. Deep-sea bioluminescence blooms after dense water formation at the ocean surface. PLOS ONE 2013:8:e67523.

18. Arístegui J, Gasol JM, Duarte CM, Herndld GJ. Microbial oceanography of the dark ocean's pelagic realm. Limnol Oceanogr 2009:54:1501-1529.

19. Wilkins LGE, Leray M, O'Dea A, Yuen B, Peixoto RS, et al. Hostassociated microbiomes drive structure and function of marine ecosystems. PLoS Biol 2019;17:e3000533.

20. Mangano S, Michaud L, Caruso C, Brilli M, Bruni V, et al. Antagonistic interactions between psychrotrophic cultivable bacteria isolated from Antarctic sponges: a preliminary analysis. Research in Microbiology 2009;160:27-37.

21. Xin $Y$, Kanagasabhapathy M, Janussen D, Xue S, Zhang W. Phylogenetic diversity of Gram-positive bacteria cultured from Antarctic deep-sea sponges. Polar Biol 2011;34:1501-1512.

22. Steinert G, Busch K, Bayer K, Kodami S, Arbizu PM, et al. Compositional and quantitative insights into bacterial and archaeal communities of south pacific deep-sea sponges (Demospongiae and Hexactinellida). Front Microbiol 2020;11:716.

23. Bayer K, Busch K, Kenchington E, Beazley L, Franzenburg S, et al. Microbial strategies for survival in the glass sponge Vazella pourtalesii. mSystems 2020;5:e00473-20.

24. Busch K, Beazley L, Kenchington E, Whoriskey F, Slaby BM, et al. Microbial diversity of the glass sponge Vazella pourtalesii in response to anthropogenic activities. Conserv Genet 2020;21:1001-1010.

25. Hooper JNA, Van Soest RWM. Systema porifera. A guide to the classification of sponges. In: Hooper JNA, Van Soest RWM and Willenz P (eds). Systema Porifera. Boston, MA: Springer US; 2002. pp. 1-7.

26. Margassery LM, Kennedy J, O'Gara F, Dobson AD, Morrissey JP. Diversity and antibacterial activity of bacteria isolated from the coastal marine sponges Amphilectus fucorum and Eurypon major. Lett Appl Microbiol 2012;55:2-8.

27. Kato S, Yamagishi A, Daimon S, Kawasaki K, Tamaki H, et al. Isolation of previously uncultured slow-growing bacteria by using a simple modification in the preparation of agar media. Appl Environ Microbiol 2018;84

28. Tagg JR, Bannister LV. "Fingerprinting" beta-haemolytic streptococci by their production of and sensitivity to bacteriocine-like inhibitors. J Med Microbiol 1979;12:397-411.

29. Chen Y-L, Lee C-C, Lin Y-L, Yin K-M, Ho C-L, et al. Obtaining long $16 \mathrm{~S}$ rDNA sequences using multiple primers and its application on dioxin-containing samples. BMC Bioinformatics 2015;16:S13.

30. Li Y, Zhang L, Xian H, Zhang X. Newly isolated cellulose-degrading bacterium Achromobacter xylosoxidans L2 has deinking potential. BioResources 2019.

31. Abell GCJ, McOrist AL. Assessment of the diversity and stability of faecal bacteria from healthy adults using molecular methods. Microbial Ecology in Health and Disease 2009;19:229-240.

32. Weisburg WG, Barns SM, Pelletier DA, Lane DJ. 16S ribosomal DNA amplification for phylogenetic study. J Bacteriol 1991;173:697-703.

33. Tamura K, Nei M. Estimation of the number of nucleotide substitutions in the control region of mitochondrial DNA in humans and chimpanzees. Mol Biol Evol 1993;10:512-526.

34. Button DK, Schut F, Quang P, Martin R, Robertson BR. Viability and isolation of marine bacteria by dilution culture: theory, procedures, and initial results. Appl Environ Microbiol 1993;59:881-891. 
35. Connon SA, Giovannoni SJ. High-throughput methods for culturing microorganisms in very-low-nutrient media yield diverse new marine isolates. Appl Environ Microbiol 2002;68:3878-3885.

36. Edgar RC, Valencia A. Updating the $97 \%$ identity threshold for $16 \mathrm{~S}$ ribosomal RNA OTUs. Bioinformatics 2018:34:2371-2375.

37. Young M, Artsatbanov V, Beller HR, Chandra G, Chater KF, et al. Genome sequence of the fleming strain of Micrococcus luteus, a simple free-living Actinobacterium. J Bacteriol 2010;192:841-860.

38. Slaby BM, Hackl T, Horn H, Bayer K, Hentschel U. Metagenomic binning of a marine sponge microbiome reveals unity in defense but metabolic specialization. ISME J 2017;11:2465-2478.

39. Sunagawa S, Coelho LP, Chaffron S, Kultima JR, Labadie K, et al. Structure and function of the global ocean microbiome. Science 2015;348:1261359.

40. Sogin ML, Morrison HG, Huber JA, Welch DM, Huse SM, et al. Microbial diversity in the deep sea and the underexplored "rare biosphere." Proceedings of the National Academy of Sciences 2006:103:12115-12120.

41. Thomas T, Moitinho-Silva L, Lurgi M, Björk JR, Easson C, et al. Diversity, structure and convergent evolution of the global sponge microbiome. Nat Commun 2016;7:11870.

42. Callahan BJ, McMurdie PJ, Holmes SP. Exact sequence variants should replace operational taxonomic units in marker-gene data analysis. ISME J 2017;11:2639-2643.

43. Cho J-C, Giovannoni SJ. Cultivation and growth characteristics of a diverse group of oligotrophic marine Gammaproteobacteria. Appl Environ Microbiol 2004;70:432-440.

44. Zhou M, Dong B, Liu Q. Draft genome sequence of Psychrobacter piscatorii strain LQ58, a psychrotolerant bacterium isolated from a deep-sea hydrothermal vent. Genome Announc 2016;4:e00044-16.
45. Oger PM, Jebbar M. The many ways of coping with pressure. Res Microbiol 2010;161:799-809.

46. Balansa W, Liu Y, Sharma A, Mihajlovic S, et al. Selection of sponge-associated bacteria with high potential for the production of antibacterial compounds. Sci Rep 2020;10:19614.

47. Graça AP, Bondoso J, Gaspar H, Xavier JR, Monteiro MC, et al. Antimicrobial activity of heterotrophic bacterial communities from the marine sponge Erylus discophorus (Astrophorida, Geodiidae). PLoS One 2013;8:e78992.

48. Anteneh YS, Yang Q, Brown MH, Franco CMM. Antimicrobial activities of marine sponge-associated bacteria. Microorganisms 2021:9:171

49. Hamamoto H, Urai M, Ishii K, Yasukawa J, Paudel A, et al. Lysocin $E$ is a new antibiotic that targets menaquinone in the bacterial membrane. Nat Chem Biol 2015;11:127-133.

50. Bano SA, Naz S, Uzair B, Hussain M, Khan MM, et al. Detection of microorganisms with antibacterial activities from different industrial wastes and GC-MS analysis of crude microbial extract. Braz J Biol 2021;83:e245585.

51. Deblais L, Rajashekara G. Compound prioritization through metaanalysis enhances the discovery of antimicrobial hits against bacterial pathogens. Antibiotics (Basel) 2021;10:1065.

52. Imai Y, Meyer KJ, linishi A, Favre-Godal Q, Green R, et al. A new antibiotic selectively kills Gram-negative pathogens. Nature 2019:576:459-464.

Edited by: S. P Diggle and K. R Duncan

\section{Five reasons to publish your next article with a Microbiology Society journal}

1. The Microbiology Society is a not-for-profit organization.

2. We offer fast and rigorous peer review - average time to first decision is 4-6 weeks.

3. Our journals have a global readership with subscriptions held in research institutions around the world.

4. $80 \%$ of our authors rate our submission process as 'excellent' or 'very good'.

5. Your article will be published on an interactive journal platform with advanced metrics.

Find out more and submit your article at microbiologyresearch.org. 